\title{
Analysis of tensile behavior of recycled aggregate concrete using acoustic emission technique
}

\author{
${ }^{1}$ RISE Research Institutes of Sweden, Borås, Sweden \\ ${ }^{2}$ Universidade da Coruña, La Coruña, Spain \\ ${ }^{3}$ Chalmers University of Technology, Gothenburg, Sweden
}

Natalie Williams Portal ${ }^{1 *}$, Mathias Flansbjer ${ }^{1}$, Diego Carró-Lopez ${ }^{2}$, Ignasi Fernandez ${ }^{3}$

Received: 15 July 2020 / Accepted: 02 December 2020 / Published online: 28 December 2020

(C) The Author(s) 2020. This article is published with open access and licensed under a Creative Commons Attribution 4.0 International License.

\begin{abstract}
Recycled concrete aggregate (RCA) was processed from reinforced concrete edge beams sourced from a demolished bridge in Sweden. This material replaced different ratios of coarse aggregate in a benchmark concrete. The tensile behavior of the developed concrete mixes was characterized via monotonic and cyclic uniaxial tensile tests performed on notched cylinders. Such tensile tests allow for the quantification of the fracture energy and softening behavior of the concrete. Moreover, acoustic emission (AE) measurements were conducted in conjunction with the cyclic tests to characterize e.g. micro-crack initiation and development, as well as crack localization. The tensile behavior of the various materials was found to be similar with minimal variation in the results. However, the softening behavior suggests that the RCA materials are slightly more brittle compared to both the mother and benchmark materials, which could be indicative of differences in the interface transition zones. The corresponding AE measurements also indicated similarities between the micro-crack initiation and development for these mixes. It can be constituted that if the concrete used to produce RCA is of high quality and from one source, the resulting RAC will have adequate tensile properties with minimal variation, despite the aggregate replacement ratio.
\end{abstract}

Keywords: Recycled aggregates; Recycled aggregate concrete; Acoustic emission; Tensile behavior

\section{Introduction}

\subsection{Background}

Closed-loop thinking is paramount concerning the responsible use of concrete as a building material. Aggregates, representing around $80 \%$ of the mix volume [1], have an indirect impact on the carbon footprint of concrete and on the environment. The extraction of raw materials, e.g. quarrying of natural stone, significantly contributes to air pollution and irreversible damage to the ecology of forests and waterways. Alternatively, residual concrete or demolition concrete waste can be crushed and recycled as aggregates and applied in new concrete or as filler material; the result of this being denoted as Recycled Concrete Aggregates (RCA). A promising market has been identified for re-use aggregates stemming from construction and demolition waste (CDW) in e.g. roads, drainage and other construction projects, but it is projected that the application can also be extended to structural applications.

The production of CDW in EU is estimated to be around 0.81.2 ton/person-year; all while, the yearly consumption of new aggregates is around 5.1 ton/person [2, 3]. Currently, recycling and re-use of CDW is supported by the European Commission particularly through the Waste Framework
Directive [4], which targets $70 \%$ of recycling/re-use of CDW for 2020 [2]. Currently, Sweden is significantly below this target $[2,3]$. Based on recent data, Sweden only uses $0.6 \%$ of RCA, in contrast, the Netherlands and United Kingdom uses $43 \%$ and $30 \%$ of RCA, respectively [3].

Aggregate in Sweden is relatively inexpensive and readily available in terms of raw material sources. Swedish taxes related to natural gravel (1996) and landfill disposal (2000) have however been implemented to attempt to regulate and diversify the materials used for aggregate [5]. Recent progress regarding the legislation behind using recycled aggregates in concrete has been made, yet it also hinders the sole use of RCA. An updated version of SS 137003 [6] in combination with the main concrete standard SS-EN 206 [7] allows for increased opportunities to incorporate recycled aggregates in concrete. The highest proportions of recycled aggregate which may be used in concrete in relation to a given exposure class is specified in SS 137003 [6]. The maximum proportion (in mass fraction) of the coarse aggregate ( $>4 \mathrm{~mm}$ ) that may consist of aggregate from recycled residual materials is $50 \%$ wt. for concrete in exposure class X0. The implementation of RCA derived from crushed concrete waste is already active in the Swedish construction industry, for use in roads and parking areas, which is justified by the fact that such actions

\footnotetext{
* Corresponding author: Natalie Williams Portal, Email: natalie.williamsportal@ri.se
} 
help minimize waste disposal and extraction of raw materials for onsite production, all while reducing material costs.

The overall purpose of this work is to investigate the structural potential of RCA concrete for applications in socalled carbon neutral transport infrastructure in Sweden. The mother concrete material used was obtained by crushing edge beams from a demolished reinforced concrete bridge in Gullspång, Sweden. The aim of this paper is solely to present the analysis of the tensile behavior of Recycled Aggregate Concrete (RAC). The tensile behavior of concrete mixtures containing differing amounts of replacement RCA was characterized using monotonic and cyclic uniaxial tensile tests (UTT), which allow for the quantification of the tensile strength, fracture energy and softening behavior of concrete. Due to the inherent differences in interfacial transition zones (ITZ) in RAC versus normal concrete, it was necessary to yield a deeper understanding of the cracking behavior and underlying mechanisms. As such, acoustic emission (AE) measurements were taken in conjunction with the cyclic tests to characterize e.g. micro-crack initiation and development, as well as crack localization. AE is a widely applied technique used to study the fracture mechanism of concrete, as demonstrated by e.g. [8-10].

\subsection{Material source}

The recycled material used in this work was obtained from crushing edge beams from a demolished bridge in Gullspång, Sweden (see Fig. 1). The bridge was originally built in 1935, and due to heavy corrosion damages, it was demolished in 2016. The concrete had a remaining compressive strength of

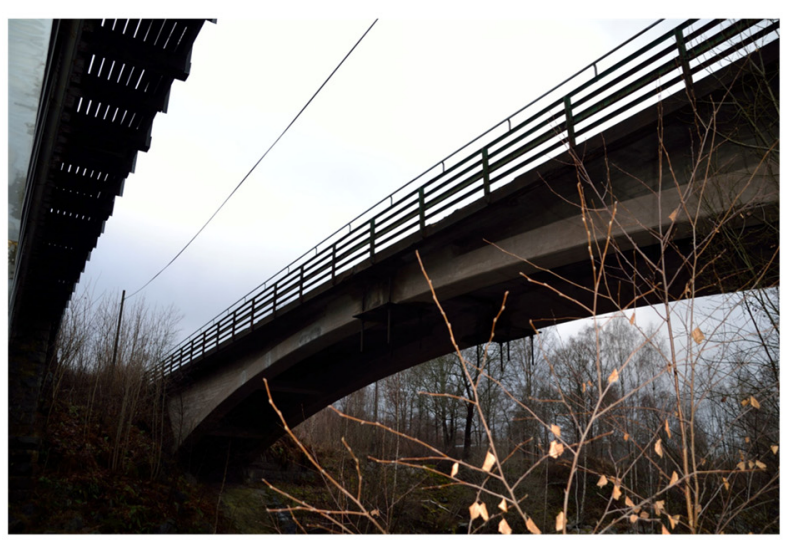

(a)
45.6 MPa (std dev 4.6 MPa), which was verified using uniaxial compression tests on concrete cores as per EN 12390-3 [11]. Smooth reinforcement bars $(\varnothing 16 \mathrm{~mm})$ with end hooks and stirrups $(\varnothing 6 \mathrm{~mm})$, typical for the given construction period, were incorporated in the beams, see [12] for further details.

\subsection{Concrete recycling}

Edge beams from the demolished bridge were processed with a transportable jaw-crusher that produced a recycled aggregate with coarse and fine fractions. A magnetic separator was attached to the crusher to recover most of the reinforcement for recycling. The processed material offered a continuous grain size distribution and it was divided into conventional sand $(0 / 4 \mathrm{~mm})$ and gravel fractions $(4 / 8,8 / 16$ and $16 / 25 \mathrm{~mm}$ ). A low percentage of the crushed material was $>25 \mathrm{~mm}$ which could undergo further crushing to yield smaller fractions. Only the coarser fraction $(>4 \mathrm{~mm})$ of this recycled aggregate was applied in the investigated RAC mixes, which is recommended in relevant EU regulations [2]. Furthermore, the acid-soluble chloride and sulphate contents of the fine and coarse fractions of the RCA were characterized according to relevant Swedish methods for aggregates, see Table 1. The chloride values meet the requirements for Type 1 aggregate, i.e. primarily from concrete, as per DIN 4226-101 [13], but cannot be specifically categorized according to SS-EN 12620 [14]. As for the sulphate values, they are within the limits for both mentioned standards $[13,14]$.

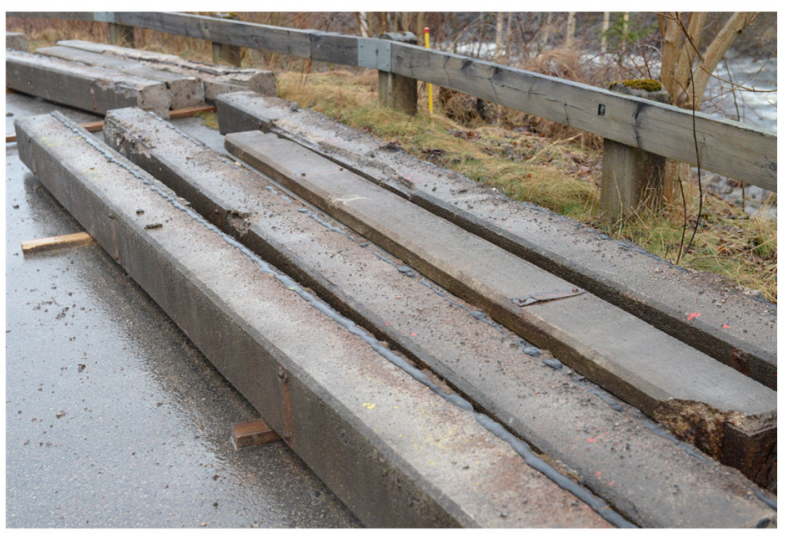

(b)

Figure 1. Overview of Gullspång bridge (a) and extracted edge beams (b).

Table 1. Chloride and sulphate contents in recycled concrete aggregate.

\begin{tabular}{|l|l|l|l|}
\hline Properties & Sand fraction (0/4) & Gravel fraction (8/16) & Method \\
\hline $\begin{array}{l}\text { Amount of acid-soluble } \\
\text { chlorides (w/w) \% }\end{array}$ & 0.013 & 0.001 & SS-EN 1744-1 [15] \\
\hline $\begin{array}{l}\text { Amount of acid-soluble } \\
\text { sulphates (w/w) \% }\end{array}$ & 0.23 & 0.11 & SS-EN 1744-1 [15] \\
\hline
\end{tabular}


The processed RCA is a combination of natural aggregate (NA) and cement paste (CP) stemming from the mother concrete. The incorporation of this type of aggregate in a new concrete will thus lead to the creation of new interfacial transition zones (ITZ) between the old CP and new CP, as well as the NA and new $C P$, as idealized in Fig. 2. Furthermore, there is the presence of an existing ITZ between the NA and old CP that is integrated in the new mixture. It has been observed that the porosity in the ITZ between RCA and CP is larger than that found in the case of NA and CP [16].

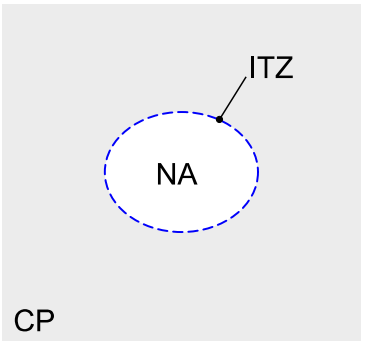

(a)

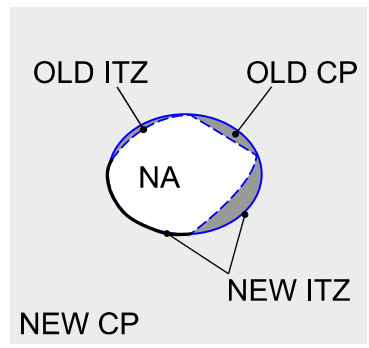

(b)
Figure 2. Idealized interaction and interfacial transition zones (ITZ) between natural aggregate (NA) with cement paste (CP) (a) and recycled aggregate with new cement paste (CP) (b).

\subsection{Recycled aggregate concrete}

The effect of recycled aggregates in concrete with $0 \%, 20 \%$, $50 \%$ and $100 \%$ of coarse recycled aggregates was analyzed. The concrete composition also included natural granitic sand $(0 / 4 \mathrm{~mm})$ and natural gravel $(8 / 16 \mathrm{~mm})$ as base materials. The cement used was a CEM I $42.5 \mathrm{R}$, which is very common in Swedish practice. To achieve acceptable workability a naphtalenesulfonate additive was used.

The benchmark concrete mixture applied is provided in Table 2. The quantity of cement was $365 \mathrm{~kg}$ per cubic meter which is acceptable for aggressive environments. The $\mathrm{w} / \mathrm{c}$ ratio was 0.47 and was kept constant for all the coarse aggregate replacement $(0 \%, 20 \%, 50 \%, 100 \%)$. The procedure to calculate the different mixes was to substitute the volume of the gravel with recycled gravel.

The natural aggregates had a reduced value of absorption, specifically $0.5 \%$ for the natural gravel and $0.3 \%$ for the natural sand. As for the recycled gravel, a value of absorption of $4.1 \%$ was measured, which is considered low for recycled aggregates [17].

\section{Uniaxial tensile tests}

\subsection{Test description}

The tensile behavior of the investigated concrete materials was obtained using uniaxial tensile tests (UTT). Such tensile tests allow for the quantification of the tensile strength, fracture energy and softening behavior of the concrete. Testing was performed on notched cylinder specimens with fixed end conditions following the recommendations given by RILEM $[18,19]$. In addition to monotonic tensile tests, cyclic tensile tests were performed on specimens containing the RCA and benchmark materials. The mother concrete was not tested cyclically due to a limited number of available specimens.

As per Fig. 3, the tensile fracture process of concrete can be subdivided into four stages as defined in [20]; (I) elastic stage and (II) stable micro cracking in the pre-peak regime, and (III) unstable macro cracking and (IV) bridging in the post-peak regime, i.e. softening behavior. The transitions between the different phases are however generally ambiguous and the phases are found to overlap. The fracture energy is defined as the energy needed to create one-unit of crack area, corresponding to the area under the softening curve, i.e. stress-crack opening relation.

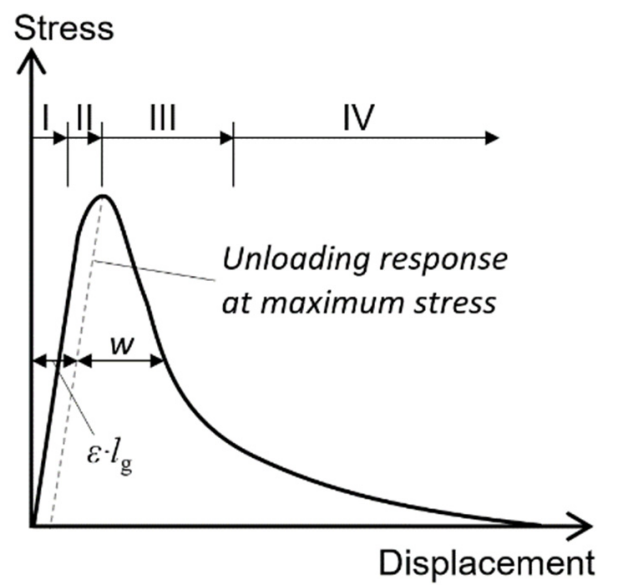

Figure 3. Schematic representation of different phases of the cracking process in a typical stress-displacement relationship.

Table 2. Mix composition for benchmark concrete ( $0 \%$ coarse aggregate replacement) [17].

\begin{tabular}{|l|l|l|l|}
\hline Material & Volume [L] & Specific gravity $[-]$ & Weight $\left[\mathrm{kg} / \mathrm{m}^{3}\right]$ \\
\hline Cement & 119.7 & 3.05 & 365.0 \\
\hline Water & 171.6 & 1.00 & 171.6 \\
\hline Natural Sand (0/4) & 355.9 & 2.65 & 943.1 \\
\hline Natural Gravel (8/16) & 347.7 & 2.62 & 911.0 \\
\hline Recycled Gravel & - & - & - \\
\hline Additive Glenium 5118 & 5.2 & 1.10 & 3.7 \\
\hline Total & 1000.0 & - & 2394.3 \\
\hline
\end{tabular}




\subsection{Test specimens and preparation}

For the RAC and the benchmark materials, the specimens were manufactured from cast cylinders, while the specimens of the mother concrete were manufactured from cores taken from the edge beams. The top and bottom faces of the cylinders were face-ground to the final length to achieve plane parallel surfaces. The cylinder specimens had a final length of approximately $100 \mathrm{~mm}$ and a diameter of $100 \mathrm{~mm}$. At the mid-section of the cylinders, a $10 \mathrm{~mm}$ deep and $5 \mathrm{~mm}$ wide circumferential notch was cut with a diamond blade (see Fig. 4). The diameter across the notch was measured at three separate locations along the perimeter; the average was used to calculate the cross-sectional area at the notch.

Each specimen was glued to a lower loading plate using a "glue device" to ensure that the center lines of the plate and specimen coincided, and perpendicularity between the face of the loading plate and the center axis of the specimen. The lower load plate, together with the glued-on specimen, was then bolted to the machine. Finally, the upper loading plate, which was already attached to the machine, was glued to the top of the specimen. Hence, any small deviation from parallelism between the end faces of the specimen and the loading plates are accommodated by the adhesive layers, yielding a perfect fit between the specimen and the loading plates. The maximum difference in adhesive thickness over the area was approximately $0.1 \mathrm{~mm}$, i.e. deviation from the specimen end faces being parallel. The adhesive used was X60 by HBM. The adhesive was set for at least 30 minutes before testing to ensure sufficient strength.

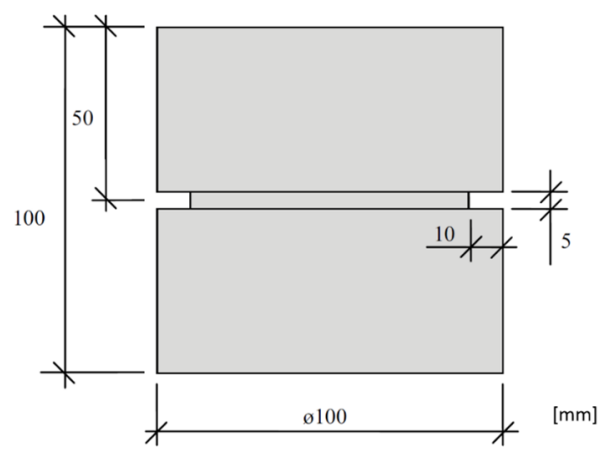

Figure 4. Uniaxial tensile test specimen geometry.

\subsection{Test setup and performance}

The tests were displacement controlled and carried out in a GCTS servo-hydraulic machine with a high-stiffness load frame. They were conducted using a moment stiff loading device to suppress rotations of the loading plates that could otherwise lead to bending failure. The device was pretensioned with a load of $150 \mathrm{kN}$. The load cell used was rated up to $200 \mathrm{kN}$ and the accuracy of the load measurement was within $1 \%$. The displacement was measured locally over the notch with three inductive displacement transducers with a gauge length, $l_{g}$, of $31 \mathrm{~mm}$. The transducers had a measuring range of $\pm 2.50 \mathrm{~mm}$ and a relative error of less than $1 \%$, which is in accordance with the recommendations. The gauges were approximately centered over the location of the notch. A photo of the test setup is shown in Fig. 5 a.

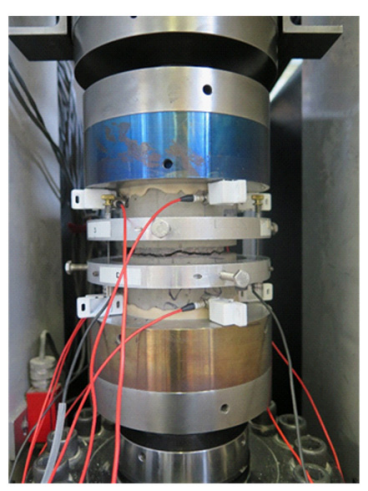

(a)

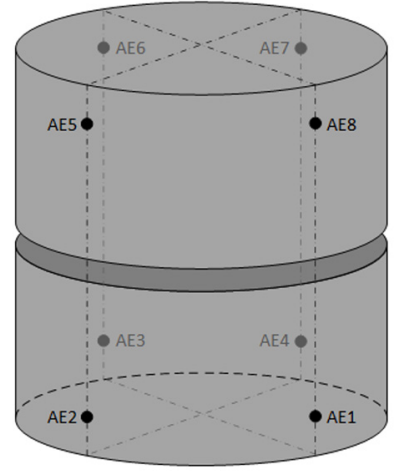

(b)
Figure 5. Uniaxial tensile test setup with $A E$ sensors during cyclic testing (a) and schematic of $A E$ sensor locations and numbering on the specimen (b).

The average value of the three displacement transducers was used for the displacement control. The maximum difference between the individual displacement transducers was found to be less than $10 \%$ of the mean displacement, which is in accordance with the recommendations to fulfill the requirement of sufficient bending stiffness of the machine [19]. In the monotonic tensile loading tests, the displacement was applied at a rate of $0.005 \mathrm{~mm} / \mathrm{min}$ up to a displacement of $\delta=0.05 \mathrm{~mm}, 0.02 \mathrm{~mm} / \mathrm{min}$ in the range $0.05<\delta \leq 0.1$ $\mathrm{mm}$, and then increased to $0.1 \mathrm{~mm} / \mathrm{min}$ for the remaining part of the test until $0.5 \mathrm{~mm}$ was reached.

In the cyclic tensile loading test, four crack closing sequences were performed during the post-peak regime according to the schematic representation shown in Fig. 6; the peak being the tensile strength $f_{\mathrm{ct}}$. During crack opening, the displacement rate was $0.005 \mathrm{~mm} / \mathrm{min}$ up to $\delta=0.1 \mathrm{~mm}, 0.1$ $\mathrm{mm} / \mathrm{min}$ in the range $0.1<\delta \leq 0.5 \mathrm{~mm}$, and then increased to $0.3 \mathrm{~mm} / \mathrm{min}$ for the remaining part of the test until complete fracture was achieved, i.e. total separation of the two crack surfaces. The stress levels indicating the start of the crack closing sequences in Fig. 6 were chosen as $\sigma_{1}=2.6, \sigma_{2}=2.0$, $\sigma_{3}=1.4$ and $\sigma_{4}=0.8 \mathrm{MPa}$. During the crack closing sequences, the displacement rate was $-0.005 \mathrm{~mm} / \mathrm{min}$. When the compressive stress of $\sigma_{\min }=1 \mathrm{MPa}$ was reached, the loading was reversed to crack opening.

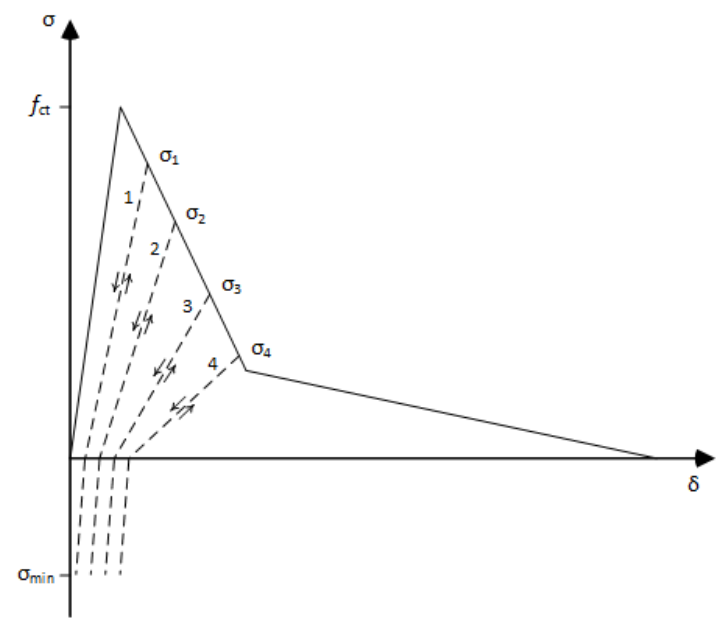

Figure 6. Schematic representation of the cyclic loading sequences. 
The crack opening $w$, in the post-peak regime, was evaluated according to [18] by subtracting the elastic deformation $\delta_{\mathrm{e}}$ from the measured displacement $\delta$ as per Eq. (1) being a function of tensile stress $\sigma$ :

$$
w=\delta-\delta_{e}=\delta-(\sigma / E) I_{g}=\delta-\sigma / K
$$

where $\sigma$ is the tensile stress, $E$ is the modulus of elasticity and $l_{\mathrm{g}}$ is the gauge length. Since the notch hampers the direct measurement of the modulus of elasticity in tension, the ratio $E / I_{\mathrm{g}}$ was replaced by the elastic stiffness $K$, which was evaluated directly from the tensile stress-displacement relationship as the secant modulus between origin and $0.45 f_{\mathrm{ct}}$. The fracture energy, $G_{\mathrm{F}}$, was calculated from the area under the stress-crack opening curve as per Eq. (2):

$$
G_{F}=\int \sigma(w) d w
$$

\subsection{AE measurements}

An eight-channel Micro-II Digital AE system and the software AEwin by Physical Acoustics Corporation was used for measuring and analyzing of AE. The AE activity was monitored by a total of eight AE sensors (Micro-30S) during tensile testing, four sensors placed close to each end face according to Fig. 5b. These miniature resonant sensors, having a frequency of $300 \mathrm{kHz}$, are suitable for use in smaller test specimens. A pre-amplification of $40 \mathrm{~dB}$ and a fixed threshold level of $50 \mathrm{~dB}$ were used, which are user-specified values determined based on experience to capture relevant mechanisms and to avoid noise from other sources. The main hit detection parameters are peak definition time (PDT), hit definition time (HDT) and hit lockout time (HLT). These were set to PDT $=100 \mu \mathrm{s}, \mathrm{HDT}=200 \mu \mathrm{s}$ and HLT $=200 \mu \mathrm{s}$ for all tests. At the time of each registered $A E$ hit, the load, actuator displacement and displacement of the three transducers were also recorded in the AE system. In addition to the parametric $A E$ evaluation, the waveform of every hit was recorded and stored for all channels with 1 MSPS sampling rate. A 3D localization algorithm was used to determine the approximate location of the AE events. The location algorithm analyses the arrival time difference of the hits in an event to calculate the source location. The arrival time was defined as the first threshold crossing of the hit waveform. The average material wave velocity was evaluated for each specimen by an auto sensor test (AST) procedure. In this method, one sensor is used as a pulser, while the rest act as receivers, and so forth. This test gives the arrival time difference between each sensor, and by knowing the distances, the wave velocity can then be determined.

\section{Experimental results}

\subsection{Monotonic tensile tests}

The five different concrete materials described in Sections 1.2 and 1.4 were studied. The tensile behavior of the concrete, including the softening branch, was evaluated from uniaxial tensile tests performed on notched cylinder specimens with fixed end conditions as described in Section 2. The tensile stress-displacement relationships are shown in Fig. 7 for the mother concrete and Fig. 8 for benchmark (0\%), 20\%, 50\% and $100 \%$. The tensile strength, $f_{\mathrm{ct}}$, and the fracture energy, $G_{\mathrm{F}}$, are summarized in Table 3.

Table 3. Monotonic tensile test result summary.

\begin{tabular}{|l|l|l|l|l|l|}
\hline Concrete & Specimen ID & $f_{\mathrm{ct}}[\mathrm{MPa}]$ & Avg (st dev.) & $G_{\mathrm{F}}\left[\mathrm{Nm} / \mathrm{m}^{2}\right]$ & Avg (st dev.) \\
\hline Mother concrete & MC-1 & 2.9 & & 232 & \\
\hline & MC-2 & 2.4 & & 230 & \\
\hline & MC-3 & 2.6 & & 153 & \\
\hline & MC-4 & 3.8 & $2.9(0.5)$ & 306 & 230 (54) \\
\hline & RT-1 & 3.0 & & 157 & \\
\hline & RT-3 & 3.4 & & 157 & \\
\hline & RT-4 & 3.4 & $3.3(0.2)$ & 212 & $175(26)$ \\
\hline & R20T-1 & 3.9 & & 132 & \\
\hline & R20T-2 & 4.2 & & 136 & \\
\hline & R20T-3 & 4.1 & $4.1(0.1)$ & 126 & 131 (4) \\
\hline & R50T-1 & 3.1 & & 131 & \\
\hline & R50T-2 & 3.2 & & 105 & \\
\hline & R50T-3 & 3.7 & $3.3(0.3)$ & 137 & $124(14)$ \\
\hline & R100T-1 & 3.1 & & 146 & \\
\hline & R100T-2 & 3.1 & & 145 & \\
\hline & R100T-3 & 3.2 & $3.1(0.1)$ & 155 & $149(5)$ \\
\hline
\end{tabular}


It can be noted that there is no major difference in the tensile behavior between the tested materials with respect to both strength and softening behavior. For all specimens, a nonlinear stage of varying degree can be observed in the stressdisplacement relation before peak stress, which is related to micro-cracking. Hence, there is no obvious difference in performance between the specimens with differing amounts of RCA replacement and the RCA materials also seem comparable to the benchmark material. However, the somewhat steeper softening curve that can be observed and the slightly lower fracture energy suggest that the mixes with RCA materials are a bit more brittle compared to both the benchmark and mother materials. It can be presumed that this increase in brittleness can be caused by the presence of additional weaker transition paths due to existing ITZs and new ITZs between old cement paste and natural aggregate. Further microscopic analysis would however be necessary to explain and quantify these differences.

In general, there is a larger scatter in both the tensile strength and fracture energy for the specimens from the mother material compared to the RCA and benchmark materials. For instance, specimen MC-4 exhibits noticeably higher tensile strength and fracture energy compared to the other specimens of the mother material. The higher fracture energy and the larger scatter is a consequence of the larger aggregates contained in the mother material, which especially affects the aggregate bridging taking place during the tail of the softening. Larger aggregates in this case are characterized as having a diameter of up to approximately 64 $\mathrm{mm}$. Hence, the size and position of the larger aggregates in relation to the ligament area may have a significant influence on the fracture energy. Furthermore, since the cores were taken from different locations of the edge beam, material variations could be caused by differing batches or levels of degradation.

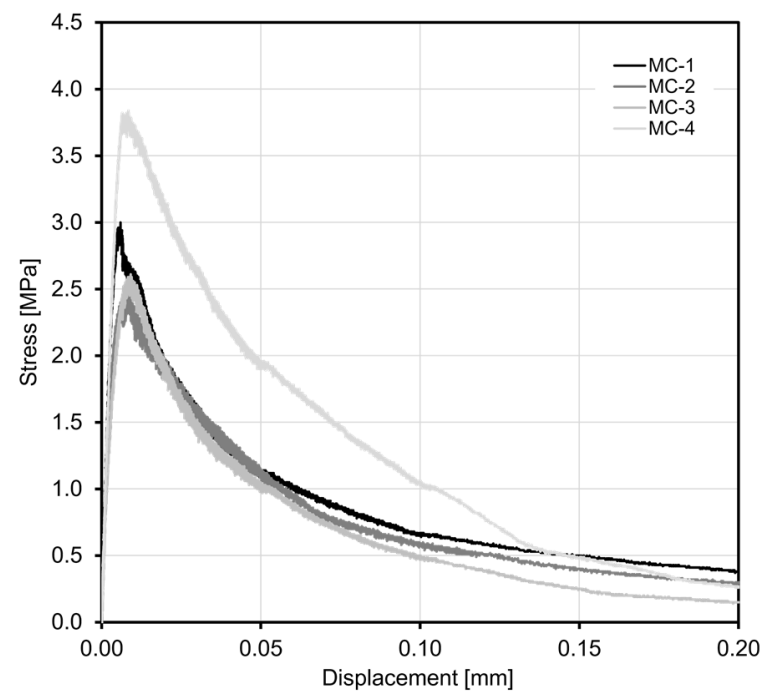

Figure 7. Stress-displacement relations for the mother concrete (MC) specimens.
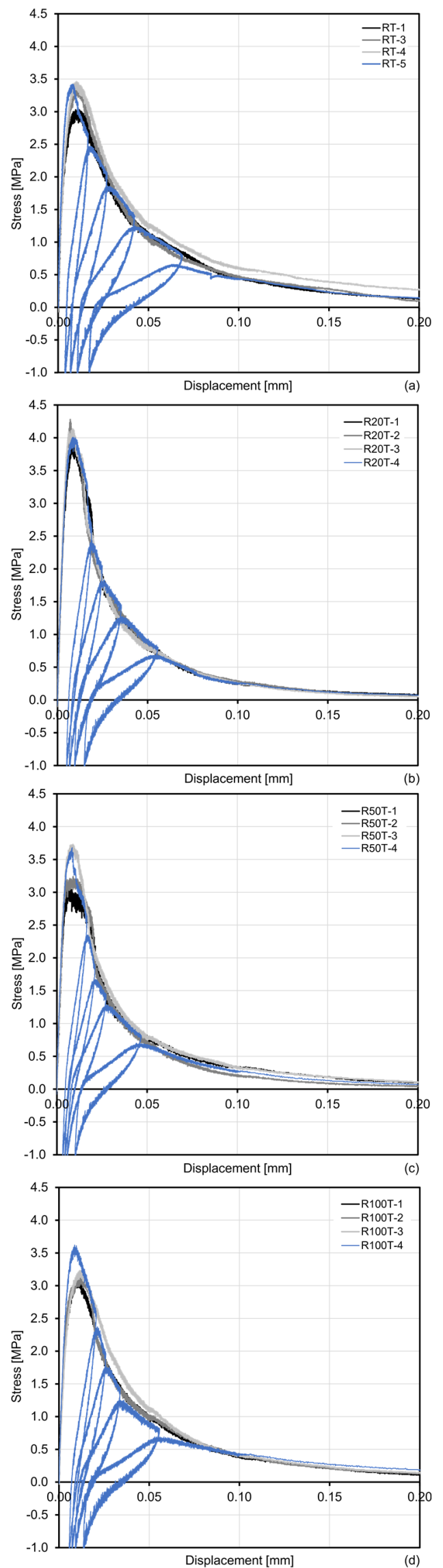

Figure 8. Stress-displacement relations for RT (a), R20T (b), R50T (c) and R100T (d). Cyclic test results are presented for RT-5, R20T-4, R50T-4 and R100T-4. 


\subsection{Cyclic tensile tests}

Cyclic tensile tests were performed on one specimen of each RCA material and the benchmark material. The mother concrete was not tested cyclically in this work. The stressdisplacement relationships from the four tests are shown in Fig. 8a-d and compared with the performed monotonic tensile tests for investigated concrete mixes.

Comparing the stress displacement relations, it can be concluded that the overall behavior of the cyclic tensile tests is very similar to the monotonic tensile tests. Furthermore, it can be observed that some irreversible deformation took place during the crack closing cycles. Also, the hysteresis effect becomes larger with each cycle. The change in slope is notable during the closing phase going from tensile to compressive loading of the fracture zone. Similar observations can be noted during the crack opening phases. As expected, the increased damage in the fracture zone results in a successively decreasing stiffness in the crack opening phase for each cycle.

Fig. 9 - Fig. 12 present the development of AE activity (hits), crack opening and stress with respect to time for the benchmark (0\%), 20\%, 50\% and $100 \%$ mixes, respectively. For clarity in the figure, the time is limited to the first $4000 \mathrm{~s}$ of testing. The macro crack initiation that is assumed to take place at peak stress is marked with a dashed line, while the crack closing phases are highlighted using grey zones.
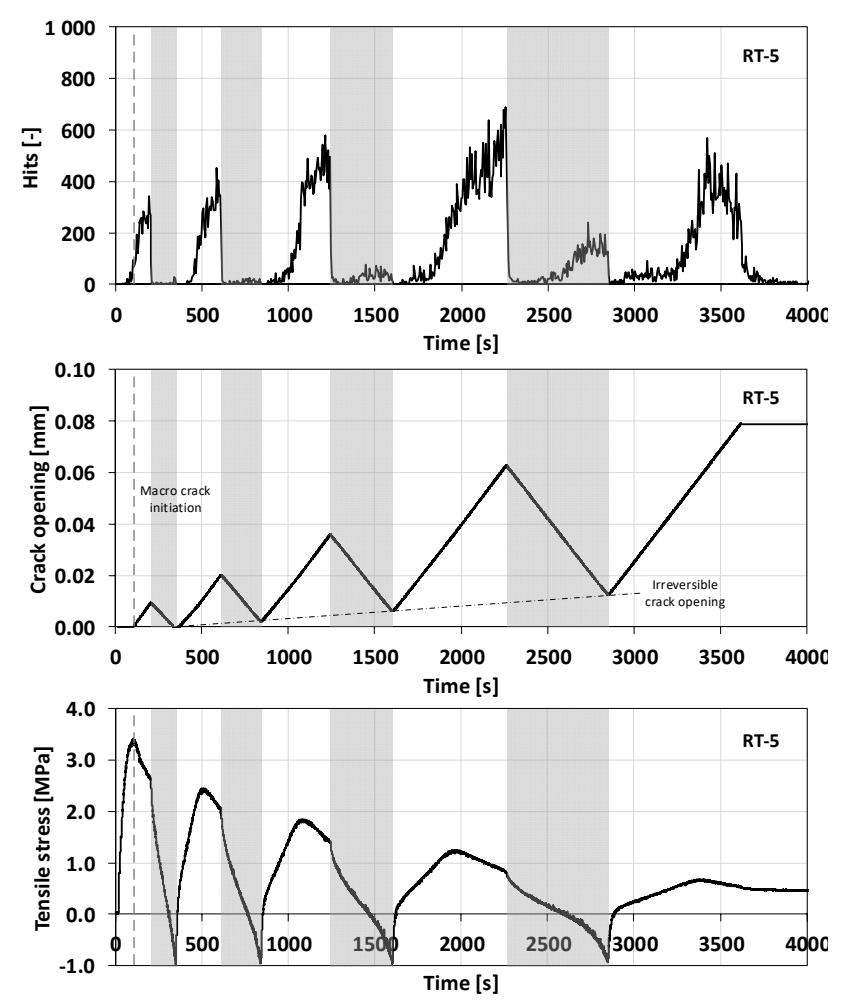

Figure 9. Cyclic tensile test results summarized as Hit-time relation (upper), Crack opening-time relation (middle) and Stress-time relation (lower) for $\mathrm{RT}-5$.
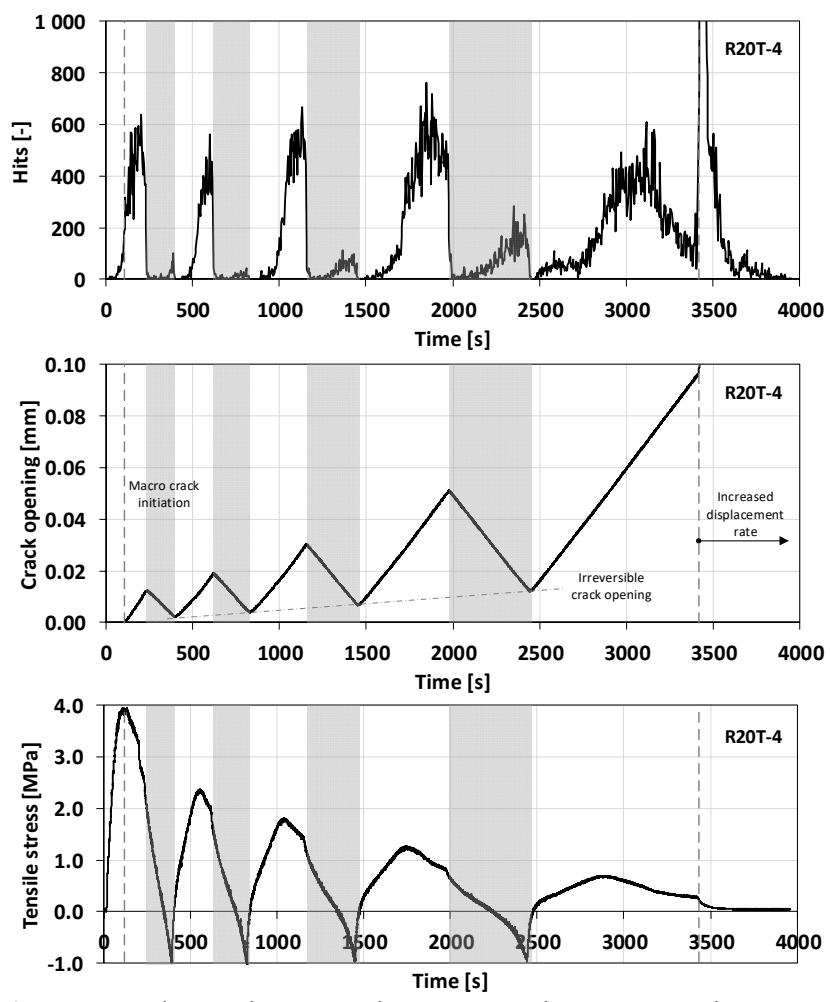

Figure 10. Cyclic tensile test results summarized as Hit-time relation (upper), Crack opening-time relation (middle) and Stress-time relation (lower) for R20T-4.
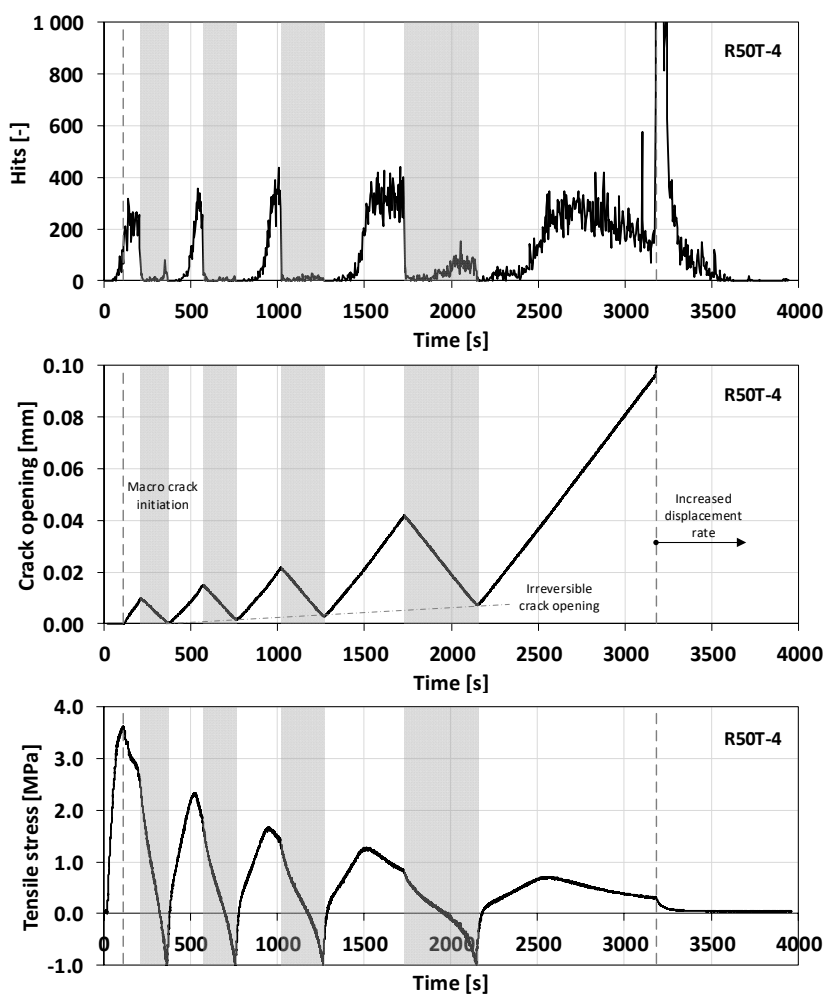

Figure 11. Cyclic tensile test results summarized as Hit-time relation (upper), Crack opening-time relation (middle) and Stress-time relation (lower) for R50T-4. 

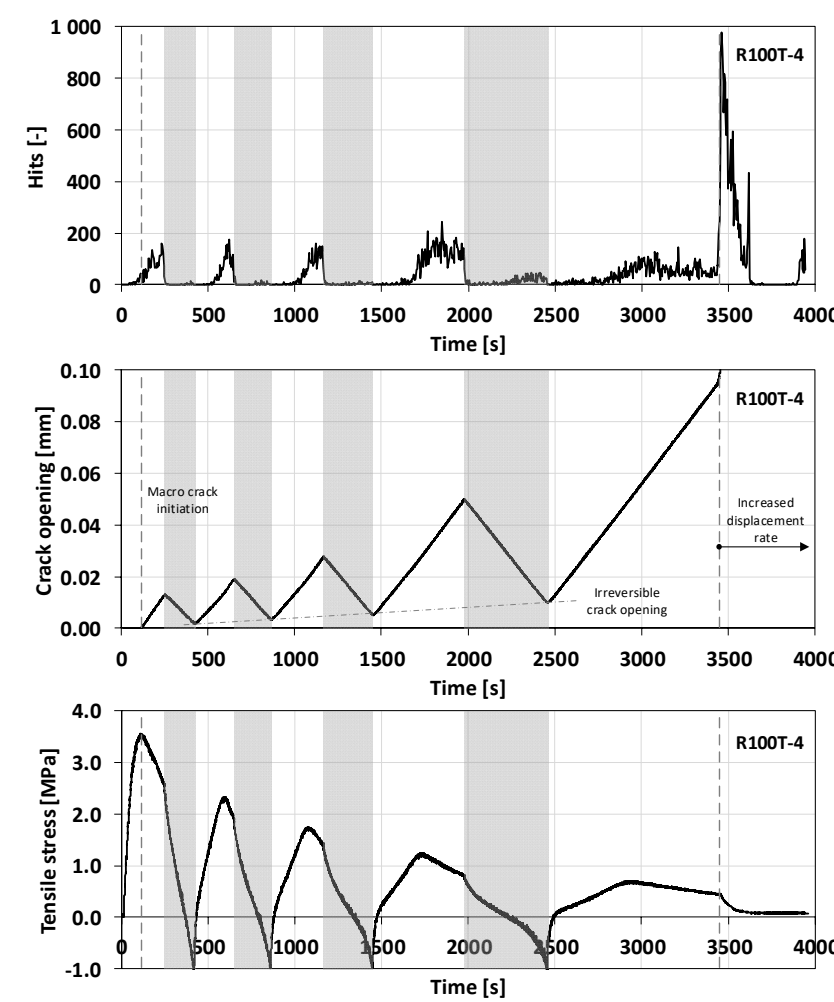

Figure 12. Cyclic tensile test results summarized as Hit-time relation (upper), Crack opening-time relation (middle) and Stress-time relation (lower) for R100T-4.
The AE activity is zero during the first elastic stage in the prepeak regime but increases during the second stage associated with micro-crack initiation taking place shortly before peak stress. The AE activity increases rapidly at the macro-crack initiation around peak stress. The relation between stress and $A E$ activity (cumulative hits) during the initial fracture process with micro and macro-crack initiation is presented in more detail in Fig. 13, for the tested specimens, namely RT-5, R20T4 , R50T-4 and R100T-4. The figures depict the first $200 \mathrm{~s}$ of testing.

There is a clear reduction in AE activity as soon as the crack closing cycle starts (marked by a grey zone), and the tensile stress is unloaded (see Fig. 9 - Fig. 12). The activity is much lower during the closing phases compared to the opening phases, although the activity increases somewhat when the fracture zone becomes subjected to compressive stress. In the subsequent crack opening phase, the AE activity is initially small, but increases significantly at a crack opening smaller than the maximum crack opening that was achieved during the former cycle, i.e. crack opening at the start of the previous crack closing phase. This activity signifies the activity in the damage zones before reaching the previous maximum crack opening and the level of increase in activity becomes higher with each cycle.
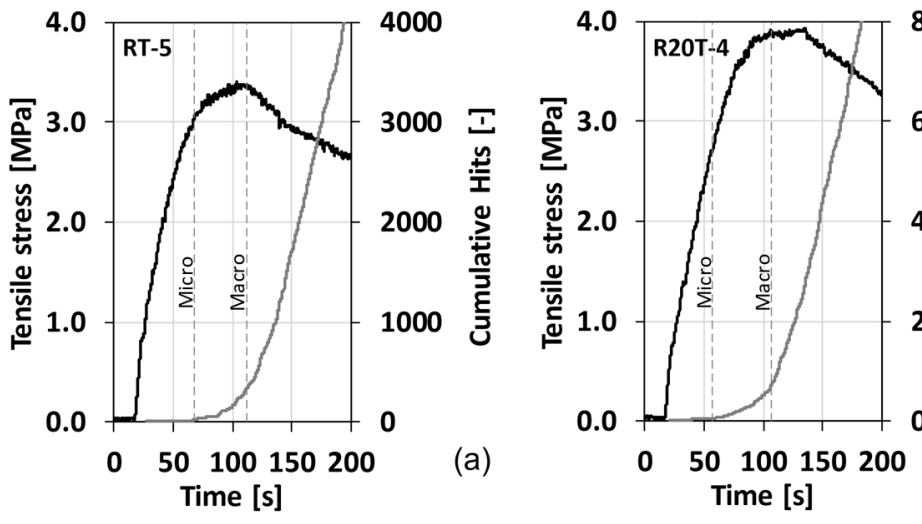

8000
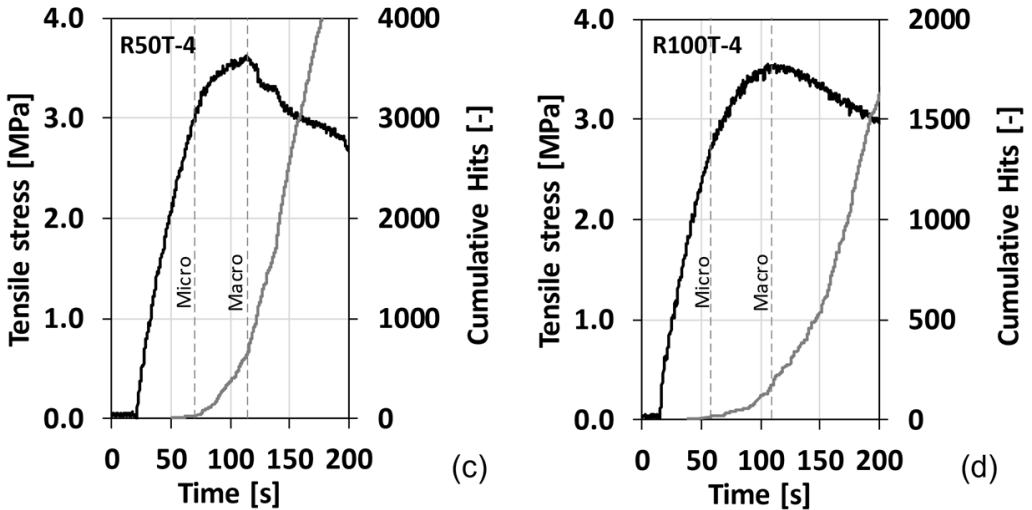

Figure 13. Stress (black line) and cumulative hits (grey line) versus time for RT-5 (a), R20T-4 (b), R50T-4 (c) and R100T-4 (d). The approximate initiation of micro- and macro-cracking are indicated by dashed lines. 

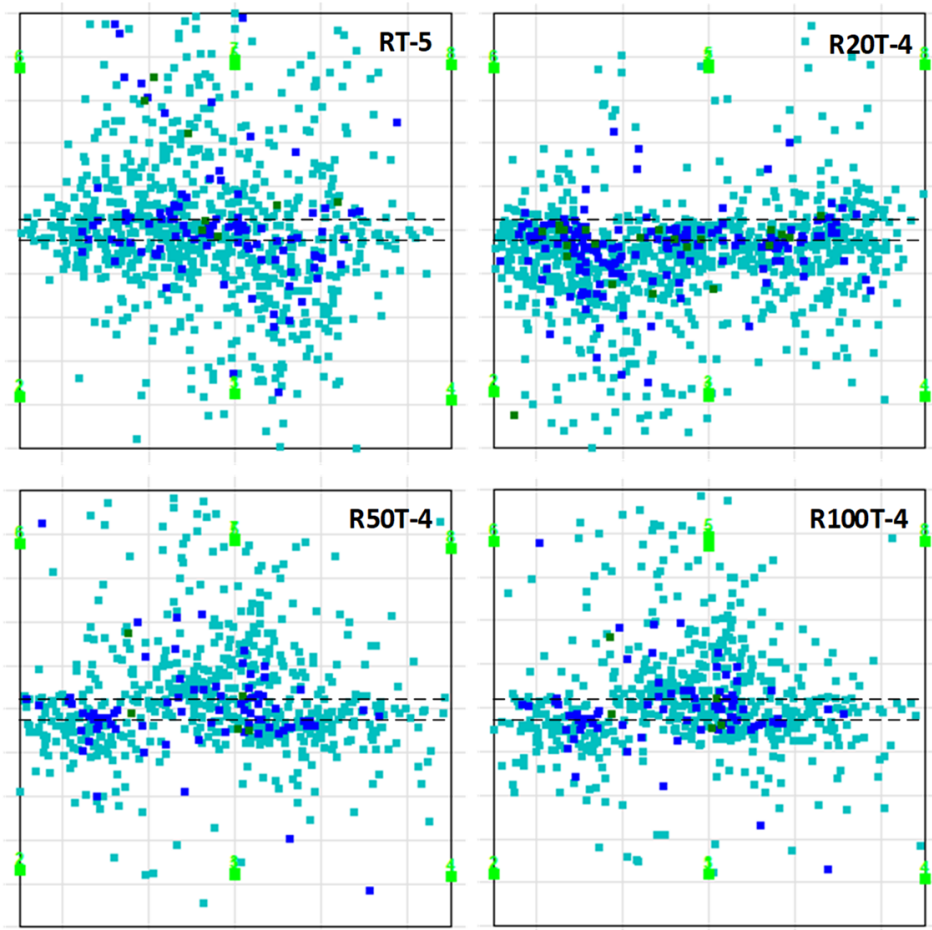

$>70.0>80.0>90.0>100.0$

Figure 14. Projection of the location of all events with an amplitude above $70 \mathrm{~dB}$ for RT-5, R20T-4, R50T-4 and R100T-4. The location of the notch is indicated by dashed lines and the position of $A E$ sensors are indicated by light green squares.

From the crack opening diagrams in Fig. 9 - Fig. 12, the irreversible crack opening increases for each crack closing cycle for all specimens. This is likely related to an increased amount of debris and mismatch in the fracture zone. Also, the stiffness during the closing phase becomes lower for each cycle, which seems logical if the amount of debris to compact and crush successively increases. This so-called compacting or crushing effect is also clearly reflected in the $A E$ measurements as an increase in AE activity for each closing cycle.

The overall characteristics of the AE activity are rather similar, but the amount of AE activity differs slightly between the specimens. When comparing the results from R20T-4, R50T-4 and R100T-4, there is a tendency that the amount of $\mathrm{AE}$ activity decreases with increased amount of RCA replacement. This observation might indicate a slight difference in the fracture process associated to the RCA, as also indicated by the monotonic tests. To ascertain the underlying causes of these differences, visual techniques would need to be applied during testing, e.g. microscopy or digital image correlation.

Moreover, the displacement rate was increased at a displacement of $0.1 \mathrm{~mm}$, which resulted in a direct increase of $A E$ activity in the form of increased hit rate in the hits-time diagrams (see e.g. Fig. 9). For specimen RT-5, this change in displacement rate was slightly delayed due to a shorter unforeseen pause in the test procedure at a displacement around $0.08 \mathrm{~mm}$. As such, this resulting increase in AE activity was not related to a specific change in the cracking process, but rather due to an intensified crack activity related to the increased loading rate.
AE activity can be registered during the entire softening branch, also for larger crack openings where the stress transfer between the fracture surfaces is very limited. During the last stage (IV) related to gradual opening of the macrocrack, the AE activity is mainly caused by the bridging effect of the aggregate particles.

As stated, a 3D localization algorithm was used to determine the approximate location of the AE events. The average wave velocity used in the localization calculations was determined for each specimen: 3900 m/s for RT-5, 3960 m/s for R20T-4, $3900 \mathrm{~m} / \mathrm{s}$ for R50T-4 and $3600 \mathrm{~m} / \mathrm{s}$ for R100T-4. It is also important to note, that the material was assumed to be isotropic having an average wave velocity; this, in turn, limits the accuracy in localization. A projection of the location of all events with an amplitude above $70 \mathrm{~dB}$ is shown in Fig. 14 . Although, it is difficult to correlate the $A E$ events with the exact geometry of the real cracks, events with higher amplitudes (> $70 \mathrm{~dB}$ ) can be correlated to the location of the developing fracture zone in the notched region. As such, the recorded data is indicative of the actual damage mechanisms in the fracture process zone. The lower amplitude events ( $\leq$ $70 \mathrm{~dB}$ ) are more scattered in the specimens. The lower amplitude signals are more sensitive to attenuation when they travel through the material and as such it becomes harder to define the exact arrival time at the sensors making them more difficult to localize. 


\section{Conclusions}

Based on the conducted uniaxial tensile tests, no significant differences in the tensile behavior were noted between the specimens with different amounts of RCA replacement. The tensile behavior of the RCA materials was also comparable to the benchmark material. However, the observed softening behavior suggests that the RCA materials are slightly more brittle in comparison to both the mother and benchmark materials, which could be indicative of differences in the ITZs.

Furthermore, it was demonstrated that the AE activity measured during the cyclic tensile tests could be related to the different stages of the fracture process, associated with micro-crack initiation in the pre-peak regime, macro-crack initiation around peak stress, as well as the crack opening and crack closing cycles taking place during the post-peak regime. The AE activity also indicated similarities between the fracture process for the different mixes.

This experimental study indicates possible trends in the tensile behavior of concrete mixes with different amounts of RCA replacement, but repeatability is necessary to lead to decisive conclusions about the material characteristics of these developed mixes. Additional visual techniques in parallel with AE could help analyze the differences in ITZs pertaining to the different mixes.

Another outcome of this work is related to the concrete source used to produce RCA. Making use of high-quality RCA from a unique source was shown to result in RAC with adequate tensile properties having minimal variation, regardless of the aggregate replacement ratio.

\section{Acknowledgements}

The presented research was made possible with the support of Vinnova Infrasweden 2030: a strategic innovation program (project no. 2017-02687) and ÅForsk foundation (project no. 18-429).

\section{CRediT authorship statement}

NWP, MF, IF and DCL: Methodology, NWP, IF, DCL and MF: Investigation, NWP and MF: Writing - original draft, NWP, $\mathrm{MF}$, IF and DCL: Writing - review and editing.

\section{References}

[1] P.K. Mehta, Reducing the Environmental Impact of Concrete. Concrete International (2001) 23(10): 61-66. https://doi.org/10.1520/CCA10085J

[2] V.W. Tam, M. Soomro, A.C.J. Evangelista, A review of recycled aggregate in concrete applications (2000-2017). Constr Build Mater (2018) 172: 272-292.

https://doi.org/10.1016/j.conbuildmat.2018.03.240

[3] European Aggregates Association, Annual Review 2017-2018 (2018).

[4] European Union Regulation Directive 2008/98/EC of the European Parliament and of the Council of 19 November 2008 on waste and repealing certain Directives (Text with EEA relevance), in Off. J. Eur. Union (L 312/3) (2008). Available from: http://eurlex.europa.eu/legal-content/EN/TXT/?uri=CELEX:32008L0098.

[5] Statens geotekniska institut (SGI). Materialguiden (2017). Available from: http://www.swedgeo.se/sv/vagledning-i-arbetet/effektivaremarkbyggande/materialguiden/

[6] Swedish standard, SS 137003:2015 Betong - Användning av EN $206 \mathrm{i}$ Sverige (2015).

[7] Swedish standard, SS-EN 206:2013 Concrete - Specification, performance, production and conformity (2013).
[8] D.G. Aggelis, A.C. Mpalaskas, T.E. Matikas, Investigation of different fracture modes in cement-based materials by acoustic emission. Cem Concr Res (2013) 48: 1-8. https://doi.org/10.1016/j.cemconres.2013.02.002

[9] S. Hu, J. Lu, F. Xiao, Evaluation of concrete fracture procedure based on acoustic emission parameters. Constr Build Mater (2013) 47: 1249-1256. https://doi.org/10.1016/j.conbuildmat.2013.06.034

[10] T. Watanabe, S. Nishibata, C. Hashimoto, M. Ohtsu, Compressive failure in concrete of recycled aggregate by acoustic emission. Constr Build Mater (2007) 21(3): 470-476. https://doi.org/10.1016/i.conbuildmat.2006.04.002

[11] European standard, EN 12390-3 Testing hardened concrete - Part 3: Compressive strength of test specimens (2019).

[12] S. Robuschi, K. Lundgren, I. Fernandez, M. Flansbjer, Anchorage of naturally corroded, plain reinforcement bars in flexural members. Mater Struct (2020) 53: 38. https://doi.org/10.1617/s11527-020-01471-2

[13] German standard, DIN 4226-101 Recycled aggregates for concrete in accordance with DIN EN 121620 - Part 101: Types and regulated dangerous substances (2017).

[14] Swedish standard, SS-EN 12620+A1:2008 Aggregates for concrete (2008).

[15] Swedish standard, SS-EN 1744-1 Tests for chemical properties of aggregates - Part 1: Chemical analysis

[16] T. Le, G. Le Saout, E. Garcia-Diaz, D. Betrancourt, S. Rémond, Hardened behavior of mortar based on recycled aggregate: Influence of saturation state at macro- and microscopic scales. Constr Build Mater (2017) 141: 479-490. https://doi.org/10.1016/j.conbuildmat.2017.02.035

[17] D. Carro-López, I. Fernandez, N. Williams Portal, An old bridge transformed into a new one: Possible, recommendable? 20th IABSE Congress, New York City 2019: The Evolving Metropolis, New York (USA), 4-6 September 2019, International Association for Bridge and Structural Engineering (IABSE), 2019, 951-956.

[18] RILEM TC 187-SOC: Experimental determination of the stress-crack opening: Final report. RILEM Publ. Bagneux (2007).

[19] RILEM TC 162-TDF: Test and design methods for steel fibre reinforced concrete: Uni-axial tension test for steel fibre reinforced concrete. Mater Struct (2001) 34(235): 3-6. https://doi.org/10.1617/13628

[20] J.G.M van Mier, Concrete Fracture, a Multiscale Approach. CRC Press, Boca Raton, Florida (2012). https://doi.org/10.1201/b12968 